\title{
How Does University Teachers' Emotional Intelligence Relate To Their Self-Efficacy Beliefs?
}

\author{
MeHDi SARKHOSH
}

University of Urmia, Iran

AbBas Ali Rezaee

University of Tehran, Iran

Received: 27 February 2012 / Accepted: 28 March 2013

ISSN: $1697-7467$

\begin{abstract}
Some studies have indicated the relationship between Emotional Intelligence (EI) and self-efficacy beliefs at schools or language institutes. This study, sought to investigate this association among university teachers. 105 university teachers participated in the present study. The participants were required to complete the "Teachers' Sense of Efficacy Scale" and the "Emotional Intelligence Questionnaire". Correlation and regression analysis were conducted on the data. The results of data analysis revealed that there was a strong positive relationship between EI and self-efficacy beliefs. Furthermore, it was found that among the fifteen components of EI, three subscales of Flexibility, Optimism and Interpersonal Relationship were positive predictors of Efficacy beliefs.
\end{abstract}

Keywords: Emotional intelligence; Self-efficacy; University teachers; Flexibility; Optimism; Interpersonal relationship

¿Cómo afecta la inteligencia emocional de los profesores de la Universidad de Teherán a su auto-confianza?

RESUMEN: Algunos estudios dan pruebas de la existencia de una relación entre la inteligencia emocional (EI, siglas en inglés) y la auto-confianza en las escuelas o institutos de lenguas. Este estudio tiene como objetivo, estudiar esta relación entre los profesores universitarios. Por ello se ha solicitado la participación de 105 profesores y se les pidió que respondan a las preguntas respecto a "El sentido de los profesores sobre la gradación de eficacia" así como "el cuestionario de la inteligencia emocional". En los datos obtenidos se analizó tanto la correlación como la regresión. El resultado del análisis de los datos muestra que existe una relación positiva muy destacada entre EI y el auto-confianza. Además, se observó que tres factores subescalas de los quince componentes, es decir: la flexibilidad, el optimismo y la relación interpersonal eran considerados como los predicadores positivos de la eficacia.

Palabras clave: Inteligencia emocional, auto-eficacia, profesores universitarios, flexibilidad, optimismo, la relación interpersonal.

\section{INTRODUCTION}

Cognitive intelligence and its quintessential measure, Intelligence Quotient (IQ) test claimed a sine qua non role in research in education, However, fairly recently there has been 
a surge of interest in the concept of EI and its relationship to language teaching, learning, and a multitude of personal and affective traits. According to Bar-On (2006), EI is a type of intelligence that involves the ability to be sensitive to one's own feelings and those of others, to be in control of self, to motivate one's self and influence others, as well as to manage emotions effectively, moreover; it can be developed to promote emotional, intellectual, and professional growth.

What seems to have warranted research on EI is that teachers' role is not, any longer, restricted to the one-way transmission of knowledge, but encompasses teaching learners how to learn, augmenting their confidence, boosting their self-esteem, motivating them and organizing an appropriate learning context (Williams \& Burden, 2000). Wubbels and Levy (1991) also, argue that there is a strong nexus between teachers' affective traits and their students' emotional achievements. As the importance of EI as an affective trait and its relationship with self efficacy beliefs of teachers, during the last two decades, has been underlined in the field, the number of studies on the relationship between EI and efficacy beliefs has been on the rise: A number of researchers (e.g., Chan, 2004; Fabio \& Palazzeschi, 2008; Penrose, Perry, \& Bell, 2007; Moafian \& Ghanizadeh, 2009; and Rastegar \& Memarpour, 2009, among others) have investigated the relationship between pre-service and in-service teachers' EI and their self efficacy beliefs and a vast majority of them have reported a strong relationship.

This study is an attempt to investigate the relationship between university Instructors' EI and their self-efficacy beliefs. However, it is unprecedented in terms of participants. Previous studies were conducted mostly at school or English institute settings. The majority investigated the relationship only among pre-service or in-service teachers or among students or teachers at school settings or English institutes and very few, if any studies have been conducted on university teachers. The dearth of research on the relationship between EI and efficacy beliefs of university instructors was the major incentive to do this study since as Schunk, Pintrich and Meece (ascited in Tseng \& Tsai, 2010) state, self-efficacy beliefs are context specific. The nature of this relationship might turn out to be quite different for university instructors since university setting is not the same, if not quite different from, as that at schools or institutes, if not quite different. The nature of the relationship between university instructors and their students can also be different. As the study by Moafian and Ghanizadeh (2009) indicates, interpersonal relationship subscale of EI is one of the strong predictors of self efficacy beliefs among institute instructors. At university settings, however, interpersonal relationship is far stronger since there is more communication between teachers and students. Students are mature enough so that professors can easily and openly communicate with them especially with post graduate students who are closely in touch with their professors while doing their thesis. Therefore, the researchers expected that there would exist a stronger relationship between EI and efficacy beliefs among these unexplored participants. 


\section{REVIEW OF RELATED LITERATURE}

\subsection{Emotional Intelligence}

The early roots of EI germinated in Thorndik's concept of social intelligence, Thorndike (as cited in Wong \& Law, 2002: 245) identified social intelligence as "the ability to understand and manage men and women, boys and girls and to act wisely in human relations". Gardner (1983) adduced eight different types of intelligence out of which personal intelligence paved the way for the flourishing of EI. From among the plethora of theories proposed for EI, Reuven Bar-On, Daniel Goleman, and Salovey and Mayer's theories have been most influential in academic circles and have contributed most to our understanding and knowledge of EI. Salovey and Mayer (1990) represented EI as the ability of people to cope with their emotions. In their words, EI is defined as "the subset of social intelligence that involves the ability to monitor one's own and others' feelings and emotions, to discriminate among them and to use this information to guide one's thinking and action" (186). EI was publicized outside academia by Goleman's publication of Emotional Intelligence (1995) and Working with Emotional Intelligence (1998). Schutte and Mallouff (1999) contended that Goleman's (1995) view of adaptive nature of EI is well understood by the idea that cognitive intelligence may assist individuals enter educational arenas; however, EI determines their success in these settings. Bar-On (1997: 14), in another definition, defined EI as "an array of non-cognitive capabilities, competencies and skills that influence one's ability to succeed in coping with environmental demands and pressures." Bar-On (1997), outlining the significance of EI in bringing about and predicting success in life in general, stressed the dire need for measuring, operationalizing and quantifying EI. Later, he developed a questionnaire to quantify EI and he called his measure Emotional Quotient Questionnaire.

\subsection{Bar-On Model of EI}

Bar-On (2000) views EI as a crucial factor in determining one's living a successful life and getting along well in the world. He identifies five major scales and fifteen subscales for it as follows:

1) Intrapersonal (self-awareness and self-expression)

- Self-Regard: To accurately perceive, understand and accept oneself

- Emotional Self-Awareness: To be aware of and understand one's emotions

- Assertiveness: To effectively and constructively express one's emotions, feelings and to defend one's right

- Independence: To be self-reliant and free of emotional dependency on others

- Self-Actualization: To strive to achieve personal goals and actualize one's potential

2) Interpersonal (social awareness and interpersonal relationship)

- Empathy: To be aware of and understand how others feel

- Social Responsibility: To identify with one's social group and cooperate with others

- Interpersonal Relationship: To establish mutually satisfying relationships and relate well with others 
3) Stress Management (emotional management and regulation)

- Stress Tolerance: To effectively and constructively manage emotions

- Impulse Control: To effectively and constructively control emotions

4) Adaptability (change management)

- Reality-Testing: To objectively validate one's feelings and thinking with external reality

- Flexibility: To adapt and adjust one's feelings and thinking to new situations

- Problem-Solving: To effectively solve problems of a personal and interpersonal nature

5) General Mood (self-motivation)

- Optimism: To be positive and look at the brighter side of life

- Happiness: To feel content with oneself, others and life in general

\subsection{Self-efficacy}

Social cognitive theory is originated from the view of human agency. In this view, individuals are considered as agents who are involved in their own development and, via their actions, they are able to make things happen. According to agency view, among other personal elements, people have self-beliefs through which they exercise some control over their thoughts, emotions, and actions. Therefore, people are both products and producers of their own environment and social system (Pajares, 2002).

Of all the thoughts that influence people's performance and functioning, and situate at the center of social cognitive theory, are self-efficacy beliefs (Pajares, 2002). Bandura (1977) defined perceived self-efficacy as the individuals' judgments of their potentials to arrange and implement courses of action to achieve designed goals, and he considered three dimensions of efficacy expectations as level, generality and strength. The level or magnitude refers to the dependence of efficacy expectations on the difficulty of a special task, such as spelling words of increasing difficulty; generality is associated with the transference of self-efficacy beliefs across activities, such as from algebra to statistics; strength is linked to the extent of certainty one possesses to perform a given task (cited in Zimmerman, 2000). The foundation of human motivation, well-being and personal achievement is provided by self-efficacy. If people believe that their endeavors can generate the desired outcomes, they have enough incentive to take action or persist in the face of adversities (Pajares, 2002).

Empirical evidence reveals that nearly every dimension of people's lives is touched with self-efficacy beliefs (Pajares, 2002) and educational environments are not the exception. In instructional contexts, teacher self-efficacy is defined as a teacher's "judgment of his or her capabilities to bring about desired outcomes of student engagement and learning, even among those students who may be difficult or unmotivated" (Sutton \& Wheatley, 2003: 783). A number of studies have inspected the role of teachers' self-efficacy beliefs in educational settings, effective teaching and student achievements. For instance, Coladarci (1992) examined the influence of teachers' sense of efficacy on commitment to teaching. In this study, general and personal efficacy beliefs were found to be the two strongest predictors of teaching commitment, along with teacher-student ratio, school climate and sex. Evers, Brouwers and Tomic (2002) studied the connection between teacher self-efficacy and burnout. They demonstrated that efficacy beliefs were negatively connected with the depersonalization and 
emotional exhaustion aspects of burnout and positively with the personal accomplishment facet. Caprara, Barbaranelli, Steca and Malone (2006) investigated the association between teachers' efficacy, their job satisfaction and students' academic achievement. The results indicated that teachers' personal efficacy plays a prominent role in their job satisfaction and students' achievement. Gibson and Dembo (as cited in Sibert, 2006) also found that teachers with high self-efficacy tend to devote more class time to academic activities, give information feedback and provide guidance to students with difficulty in understanding material more than those with lower efficacy levels.

In sum, the findings of the mentioned research illustrate the determining role that teacher efficacy beliefs play in creating a dynamic and productive academic environment which is conducive to students' learning and achievement.

\subsection{Sources for Developing Self-efficacy}

Four major sources of enhancing self-efficacy beliefs are actual performances, vicarious experiences, forms of persuasion and physiological responses. Individuals' performances are the most reliable channels for judging self-efficacy beliefs. In general, successes reinforce and failures weaken self-efficacy beliefs (Schunk \& Meece, 2005).

Attaining self-efficacy information via comparisons with other similar people and their performances is the second source of invigorating efficacy beliefs. When individuals observe that their similar persons are able to perform a task successfully, a belief may be also created in them in that they can also carry it out effectively. It is worth noting that vicarious experience has a weaker force than mastery experience because it can be negated by ensuing performance impediments (Schunk \& Meece, 2005).

The third source of enhancing efficacy beliefs is comprised of persuasive information such as others' verbal encouragement. Nonetheless, if following performances make different outcomes, its influences may be temporary. Another source of indicating efficacy beliefs is physiological signs such as heart rate and feelings of anxiety. These symptoms can reveal that one lacks the necessary skills: On the contrary, individuals may feel more self-efficacious when they experience fewer emotional symptoms (Schunk \& Meece, 2005).

\subsection{Previous Studies on the Association between EI and Teacher Self-efficacy}

Much research has been conducted on EI (e.g., Brackett \& Salovey, 2006; Carmeli, 2003; Schutte et al., 1998) and on self-efficacy (e.g., Ross, 1994; Tschannen-Moran \& Woolfolk Hoy, 2001); however, research on the relationship between the two is still meager. A number of studies have investigated the relationship between EI and teachers' self-efficacy beliefs. For instance, Chan (2004) studied the relationship between EI and perceived self-efficacy among 158 secondary school teachers. Results revealed a positive relationship between EI and selfefficacy. Fabio and Palazzeschi (2008) examined the association between occupational selfefficacy and EI among 169 Italian teachers. They concluded that the intrapersonal dimension of EI best accounts for teacher self-efficacy. Moafian and Ghanizadeh (2009) carried out a study on the connection between EI and teachers' self-efficacy beliefs in language Institutes. They selected 89 EFL teachers from among different language institutes. They concluded that there is a strong positive association between EI and teachers' self-efficacy beliefs. Rastegar 
and Memarpour (2009) conducted a study on high school EFL teachers in order to assess the relationship between EI and self-efficacy. They examined the relationship with respect to age, gender and teaching experience. They came up with a significant positive correlation between EI and self-efficacy. There was no significant difference among EFL teachers with different age, gender and teaching experience regarding their EI and self-efficacy.

Reviewing the literature on the connection between EI and teacher efficacy reveals that almost all the studies conducted so far have examined the relationship among teachers in school education or language institutes and, to the researchers' best knowledge, no research to date, has considered this association among teachers at university level. Schunk et al., (2008) maintain that self-efficacy beliefs are context specific (cited in Tseng \& Tsai, 2010). School or language institute contexts differ from university context; consequently, this may impact teachers' instructional behaviors and the influential factors that enhance their effective teaching and efficacy beliefs as was discussed in introduction. The dearth of research into the possible relations between EI and efficacy beliefs among university teachers calls for further investigations to explore this association at university level. Therefore, the present study is an attempt to probe into the nature of the relationship between self-efficacy and EI among university teachers. To this end, the following research questions were raised:

1) How does university instructors' EI relate to their sense of self-efficacy beliefs?

2) How do the different subscales of university instructors' EI relate to their sense of self-efficacy beliefs?

\section{Method}

\subsection{Participants}

The present study was done with 105 university instructors majoring in different fields at the university of Tehran-Iran. Out of 105 participants, 87 reported their age which ranges between 23 and $47(\mathrm{M}=27.97, \mathrm{SD}=3.31)$ and 84 reported their teaching experience which ranges between 0.5 and 17 years $(\mathrm{M}=2.64, \mathrm{SD}=2.40)$. Participants were all teaching at different universities throughout the country, meanwhile, studying M.A. (N=62) or Ph.D. $(\mathrm{N}=43)$ at the University of Tehran.

\subsection{Instruments}

\subsubsection{EQ test}

To evaluate language teachers' EI, the researchers employed "Bar-On EI test" which was designed by Bar-On in 1980. Bar-On EI test, called the emotional quotient inventory (EQ-i), is a self report measure of emotionally and socially intelligent behavior that provides an estimate of emotional-social intelligence (Bar-On, 1997). The test includes 133 items in the form of short sentences which measure five broad areas of skills and fifteen factorial components. It employs a five-point response scale with a textual response format ranging from 'very seldom' or 'not true of me' to 'very often' or 'true of me'. Each item has the 
value of 5 ranging to 1 . In the current study, the Persian version of EQ test was applied. According to Dehshiri (2003), this test and its subscales do have reliability and validity in Iranian culture. As he states, the questionnaire has generally good internal consistency, test-retest reliability, and construct validity. With the adapted version in Iran, the Cornbach's alpha coefficient was found to be 0.76 , and the results of the factor analysis provided some support for the inventory hypothesized structure (Dehshiri, 2003). In this study, the total reliability of the questionnaire, estimated via Cronbach's alpha, was 0.84 .

\subsubsection{Teachers' sense of efficacy scale (Long form)}

To determine teachers' efficacy level, the Teachers' Sense of Efficacy Scale, designed by Tschannen-Moran and Woolfolk Hoy, was employed. The Teachers' Sense of Efficacy Scale, also called the Ohio State Teacher Efficacy Scale (OSTES), encompasses two versions: long form (including 24 items) and short form (including 12 items). The long form - utilized in the present study - comprises three subscales: efficacy in student engagement, efficacy in instructional strategies, and efficacy in classroom management. Each subscale loads equally on eight items, and every item is measured on a 9-point scale anchored with the notations: "nothing, very little, some influence, quite a bit, a great deal." This scale seeks to capture the multi-faceted nature of teachers' efficacy beliefs in a concise manner, without becoming too specific or too general.

The total reliability and the reliability of each individual factor-reported by TschannenMoran and Woolfolk Hoy (2001) -are shown in the following table.

Table 1. Reliability reports of OSTES

\begin{tabular}{l|ccc}
\hline & Mean & Std Deviation & Alpha \\
\hline OSTES & 7.1 & 0.94 & 0.94 \\
Students Engagement & 7.3 & 1.1 & 0.87 \\
Instructional Strategies & 7.3 & 1.1 & 0.91 \\
Classroom Management & 6.7 & 1.1 & 0.90 \\
\hline
\end{tabular}

In the present study, the total reliability of the questionnaire was calculated via Cronbach' alpha which was found to be 0.93 .

\subsection{Data Collection}

The present study was conducted at the University of Tehran-Iran. Since one of the authors studies Ph.D. at this university, the researchers received warm welcome and eager participation of the participants. The participants were chosen randomly from among different fields of study. The sense of self-efficacy questionnaires together with EI questionnaires were randomly distributed among the participants. Out of 320 questionnaires (160 efficacy questionnaires \& 160 EI questionnaires) distributed, 210 questionnaires (105 efficacy questionnaires \& 105 EI questionnaires) were returned. Data collection lasted for three weeks and was conducted in December, 2010. To ensure reliability of the data, the researchers 
explained the purpose of completing the questionnaires and guaranteed that their data would be confidential. The participants' questionnaires were coded numerically and the confidentiality and anonymity considerations were observed.

\subsection{Data Analysis}

To ensure the normality of the distribution, descriptive statistics was utilized. To determine the relationship between instructors' EQ and efficacy, a Pearson Product-Moment correlation was run. To find out which components of EQ might have more predictive power in predicting instructors' efficacy, regression analyses were conducted.

\section{Results}

In order to analyze the relevant data in this experiment, the Statistical Package for Social Sciences (SPSS) was employed. The level of significance was set at 0.05 . Table 2 summarizes the descriptive statistics of the two instruments - EQ and Self-efficacy Questionnaires - utilized in this study.

Table 2. Descriptive statistics of EQ and Self-efficacy

\begin{tabular}{l|ccccc}
\hline & N & Minimum & Maximum & Mean & SD \\
\hline EQ & 105 & 345 & 605 & 476.142 & 48.494 \\
Self-efficacy & 105 & 73 & 214 & 151.666 & 26.605 \\
\hline
\end{tabular}

To investigate the correlation between instructors' Self-efficacy and EQ, a Pearson Product-Moment correlation was applied. The results indicated a relatively strong positive correlation $(\mathrm{r}=0.531, \mathrm{p}<.05)($ See Table 3$)$.

Table 3. The results of correlation between instructors' Self-efficacy and EQ

\begin{tabular}{l|cc}
\hline & Self-efficacy & Sig. \\
\hline Total EQ & $0.531^{*}$ & 0.000 \\
\hline
\end{tabular}

* Correlation is significant at the 0.05 level (2-tailed).

To examine whether there is any significant correlation between instructors' Self-efficacy and the 15 components which compose the total EQ test, a Pearson Product-Moment correlation was employed. It was found that all the 15 components of EQ test had a rather significant positive correlations with instructors' Self-efficacy and among the different components, Self-Regard $(r=0.447, p<.05)$, Interpersonal-Relationship $(r=0.444, p<.05)$, Flexibility $(\mathrm{r}=0.460, \mathrm{p}<.05)$, and Stress Tolerance $(\mathrm{r}=0.442, \mathrm{p}<.05)$ had the highest correlations with efficacy scores (See Table 4). 
Table 4. The results of correlation between the components of EQ and Self-efficacy

\begin{tabular}{l|cc}
\hline & Self-efficacy & Sig. \\
\hline Emotional Self-Awareness & $0.360^{*}$ & 0.000 \\
Assertiveness & $0410^{*}$ & 0.000 \\
Self-Regard & $0.447^{*}$ & 0.000 \\
Self-Actualization & $0.390^{*}$ & 0.000 \\
Independence & $0.327^{*}$ & 0.001 \\
Empathy & $0.254^{*}$ & 0.009 \\
Interpersonal-Relationship & $0.444^{*}$ & 0.000 \\
Social Responsibility & $0.242^{*}$ & 0.005 \\
Problem Solving & $0.370^{*}$ & 0.000 \\
Reality Testing & $0.283^{*}$ & 0.003 \\
Flexibility & $0.460^{*}$ & 0.000 \\
Stress Tolerance & $0.442^{*}$ & 0.000 \\
Impulse Control & $0.231^{*}$ & 0.018 \\
Happiness & $0.398^{*}$ & 0.000 \\
Optimism & $0.439^{*}$ & 0.000 \\
\hline
\end{tabular}

* Correlation is significant at the 0.05 level (2-tailed).

To investigate which components of EQ might have more predictive power in predicting instructors' Efficacy and how other components contribute to this model, a stepwise regression analysis was employed. The following table is the ANOVA table of regression. The magnitude of F-values and the amount of the respective p-values $(\mathrm{p}<0.05)$ indicated that the considered models were significant (See Table 5). 
Table 5. The ANOVA table of regression

\begin{tabular}{c|llllll}
\hline Model & & Sum of Squares & df & Mean Square & F & \multicolumn{1}{c}{ Sig. } \\
\hline \multirow{3}{*}{1} & Regression & 15552.950 & 1 & 15552.950 & 27.588 & $0.000^{\mathrm{a}}$ \\
& Residual & 58066.383 & 103 & 563.751 & ---- & ---- \\
& Total & 73619.333 & 104 & ---- & ---- & ---- \\
\multirow{3}{*}{2} & Regression & 21040.644 & 2 & 10520.322 & 20.409 & $0.000^{\mathrm{b}}$ \\
& Residual & 52578.690 & 102 & 515.477 & --- & ---- \\
& Total & 73619.333 & 104 & ---- & ---- & ---- \\
& Regression & 23380.660 & 3 & 7793.553 & 15.668 & $0.000^{\text {c }}$ \\
& Residual & 50238.674 & 101 & 497.413 & ---- & ---- \\
& Total & 73619.333 & 104 & ---- & --- & ---- \\
\hline
\end{tabular}

a. Predictors: (Constant), Flexibility

b. Predictors: (Constant), Flexibility, Optimism

c. Predictors: (Constant), Flexibility, Optimism, Interpersonal Relationship

d. Dependent Variable: Efficacy

As displayed in Table 6, among the 15 subscales of EQ, only three subscales; i.e., Flexibility, Optimism and Interpersonal Relationship, were found to be positive predictors of the dependent variable (Efficacy).

Table 6. The results of regression analysis for instructors' $E Q$ and their Self-Efficacy

\begin{tabular}{|c|c|c|c|c|c|}
\hline \multirow[t]{2}{*}{ Model } & \multicolumn{2}{|c|}{ Unstandardized coefficients } & \multirow{2}{*}{$\frac{\text { Standardized coefficients }}{\text { Beta }}$} & \multirow[t]{2}{*}{$\mathbf{t}$} & \multirow[t]{2}{*}{ Sig. } \\
\hline & B & Std. error & & & \\
\hline 1 & & & & & \\
\hline (Constant) & 79.771 & 13.883 & & 5.746 & .000 \\
\hline Flexibility & 2.590 & .493 & .460 & 5.252 & .000 \\
\hline 2 & & & & & \\
\hline (Constant) & 39.194 & 18.831 & & 1.922 & .057 \\
\hline Flexibility & 1.891 & .518 & .336 & 3.651 & .000 \\
\hline Optimism & 2.029 & .622 & .300 & 3.263 & .002 \\
\hline 3 & & & & & \\
\hline (Constant) & 18.255 & 20.263 & & .901 & .370 \\
\hline Flexibility & 1.438 & .550 & .255 & 2.616 & .010 \\
\hline Optimism & 1.621 & .639 & .240 & 2.536 & .013 \\
\hline $\begin{array}{l}\text { Interpersonal } \\
\text { Relationship }\end{array}$ & 1.084 & .500 & .214 & 2.169 & .032 \\
\hline
\end{tabular}


a) Dependent Variable: Efficacy

Table 7 illustrates the model summary statistics. The results revealed that the model containing the three components of EQ - Flexibility, Optimism and Interpersonal Relationship - could predict 29 percent of the instructors' self-efficacy. The R value was 0.546 which indicated the correlation coefficient between instructors' self-efficacy and the three components of EQ. Additionally, it demonstrated the effect size of the analysis which was a large magnitude (Larson-Hall, 2010). Its square value was 0.318 and its adjusted square was 0.297 . It showed that about $29 \%$ of the variation in instructors' self-efficacy could be explained by taking their EQ into account (see Table 7).

Table 7. $R$ square table for $E Q$ as the predictor of teachers' Self-efficacy

\begin{tabular}{c|cccc}
\hline Model & R & $\mathbf{R}^{2}$ & Adjusted R $^{2}$ & $\begin{array}{c}\text { Std. Error of } \\
\text { the Estimate }\end{array}$ \\
\hline 1 & $.460^{\mathrm{a}}$ & .211 & .204 & 23.74345 \\
2 & $.535^{\mathrm{b}}$ & .286 & .272 & 22.70413 \\
3 & $.546^{\mathrm{c}}$ & .318 & .297 & 22.30275 \\
\hline
\end{tabular}

a. Predictors: (Constant), Flexibility

b. Predictors: (Constant), Flexibility, Optimism

c. Predictors: (Constant), Flexibility, Optimism, Interpersonal Relationship

d. Dependent Variable: Efficacy

\section{Discussion}

The current study was carried out to examine the association between EI and self- efficacy beliefs among university instructors. In response to this question, a significant strong positive relationship was reported. This means that those instructors who feel more efficacious in their profession are the ones possessing higher levels of EI. The yielded result corroborates the findings of the studies conducted by Rastegar and Memarpour (2009) and Moafian and Ghanizadeh (2009). These studies demonstrated a positive connection between English teachers' EI and self-efficacy at high schools and language institutes respectively. Additionally, the result supports the findings of Chan (2004) and Penrose et al. (2007). These researchers also found a positive relationship between EI and self-efficacy among primary and secondary school teachers. Considering the results of different studies on EI and teacher efficacy and the findings of the present study, one can conclude that the influence of teachers' emotional dimension on their efficacy beliefs is critical and considerable regardless of the educational environment where they are teaching. To put it in a nutshell, no matter whether the teacher is teaching at primary, secondary or high schools, in language institutes or at universities, a teacher's emotional facets have a substantial role in developing his/her efficacy expectations. This is in line with Gibbs's contention. Gibbs (2002) argued that teachers' emotions and moods are a source of information that controls self-efficacy judgments. Sutton and Wheatley (2003: 339) also stated "emotions may account for a portion of the variance in self-efficacy". 
The results also demonstrated that among the 15 components of EQ, flexibility, optimism and interpersonal relationship were positive predictors of university instructors' sense of efficacy beliefs. The definition of flexibility, that is, to adapt and adjust one's feelings and thinking to new situations (Bar-One, 2006), illustrates that one should possess both affective and cognitive flexibility in order to benefit from higher levels of efficacy beliefs. This finding confirms the result of Martin and Anderson's (as cited in Cayanus, 2005) study. They found that individuals owning higher levels of cognitive flexibility enjoy higher levels of self-efficacy in classroom communication. Reaching flexibility as a positive predictor of instructors' efficacy is not far from expectation. For a university instructor, flexibility can be beneficial from three perspectives. First, it seems that flexible instructors are more open to new ideas and the latest developments in the field of teaching and also in subject matters they are teaching and are more willing to experiment with new innovations and scientific achievements to better meet the students' needs. Second, different students bring to class different dispositions and potentials and they learn differently. It seems that flexible instructors are more able to accept these differences and adapt their methods to accommodate them. If a method or strategy does not seem to be working, in contrast to their more rigid counterparts, it's more likely that they adopt alternatives. Third, in case of receiving constructive and effective views or any criticisms from their colleagues and students, such instructors appear to be more willing to accept and exploit positive points and remove their weaknesses. It is logical that the three mentioned factors increase the probability of success in teaching profession at universities which, in turn, contributes to higher sense of efficacy beliefs since, according to social-cognitive theory, the most important source of efficacy beliefs is the experience of success (Caprara, et al., 2006).

Regarding optimism, that is, to be positive and look at the brighter side of life (Bar-One, 2006), the finding is compatible with earlier empirical research and theoretical contentions. For instance, a cross-cultural study by Luszczynska, Gutiérrez-Doña and Schwarzer (2005) indicated that general self-efficacy is positively connected with optimism, self-regulation and self-esteem. Woolfolk, Hoy and Kurz (2007) also conducted research on academic optimism among American elementary teachers and demonstrated that the teachers' dispositional optimism was related to the explanation of teachers' sense of academic optimism. According to the authors, academic optimism encompasses three associated concepts, i.e., teacher sense of efficacy, teachers' confidence in students and parents, and teachers' focus on constructing a positive and challenging academic environment for students. Chan (2006) argued that the influences among possible selves, optimism, and teacher efficacy are bidirectional. Likewise, Bandura (as cited in Karademas, Kafetsios \& Sideridis, 2007) contended optimistic appraisals are facilitated by a strong sense of self-efficacy.

In view of the fact that optimism is negatively associated with anxiety and depressive symptoms (Shnek, Irvine, Stewart \& Abbey, 2001; Vickers \& Vogeltanz, 2000) instructors who are optimistic suffer less from stress, anxiety and depressive emotions and according to Schunk and Meece (2005), when individuals experience fewer emotional symptoms such as anxiety, they may feel more efficacious. Additionally, Seligman (as cited in Woolfolk Hoy et al., 2007) considered optimism as one of the important influential factors in individuals' success. He argued that optimism is as significant as talent or motivation in achievement. It seems that the same holds true for university instructors and optimism may have an important impact on their professional achievement. Optimist instructors concentrate on the positive qualities of students, classrooms, educational environments and communities (Pajares, 2001) 
and naturally exploit such potentials in the direction of boosting their effectiveness. As Karademas et al. (2007) state, "threatening stimuli may not be that concerning for optimists so as to allocate great amounts of informational resources to these stimuli" (292). Instructors' optimism at university level can also be very determining in flourishing students' potentials and talents. It appears that optimist instructors trust in their students' capabilities and potentials more easily. Consequently, it is more common, among these professors, to give scientific responsibilities to their students both inside and outside the class. Receiving such confidence from instructors and professors energizes and stimulates students to do their best and perform the responsibilities as best as possible. They also benefit from other positive consequences such as becoming independent learners, identifying their own strengths and weaknesses. By the same token, such professors provide appropriate conditions for further success which, in turn, leads to higher levels of efficacy beliefs.

Concerning interpersonal relationship, that is, to establish mutually satisfying relationships and relate well with others (Bar-One, 2006), the result of the study concurs Moafian and Ghanizadeh's (2009) study in which they found a positive relationship between selfefficacy and the interpersonal component of EI among EFL teachers. In general, professors with high levels of interpersonal skills are more likely to be able to utilize the four sources of enhancing efficacy beliefs. Teaching and learning are interactive processes taking place in the context of teacher-student relationship (Jarvis, 2005) and teachers function in a dynamic social environment. There are a number of studies highlighting the importance of teachers' interpersonal relationships with their students on teaching success. For example, Lowman (1996) showed that interpersonal rapport is one of the main characteristics of exemplary teachers. Reid and Johnson (as cited in Jarvis, 2005) illustrated that, from university students' point of view, the instructors' approachability and quality of interactions were important factors in effective teaching. Mortiboys (2005) also discussed if students have better relationship with teachers, it is less probable that they drop out from courses. What Mortiboys has mentioned is more tangible for university students, especially B.A. students who are younger and do not possess the emotional and cognitive maturity of M.A and P.h.D students. As it is the case, in many parts of the world including Iran, when students are accepted at universities, some of them have to leave their hometowns and live in another city far from their family. Most of them have not had such an experience before and begin to miss their home, feel homesick and become emotionally more vulnerable. Most of the time, this issue affects their academic achievements negatively. In such cases, university professors, via constructing a warm and supportive relationship with students, can compensate for the created affective gap and can prevent students' academic failure. Thus, instructors with positive interpersonal relationships can easily enjoy the benefits of mastery experience source. In addition, through maintaining healthy interpersonal relationship with colleagues, instructors can benefit from the second and third sources of efficacy beliefs, i.e., vicarious experience and verbal persuasion. In this case, by receiving invaluable experiences of colleagues and their encouragement in general and in face of difficulties in particular, they can perform better and easily overcome the obstacles. Additionally, due to creating an intimate supportive atmosphere inside the class with students and outside the class with colleagues and other staff of university, such instructors reduce the probability of producing negative feelings and emotions such as stress and anxiety; consequently, they enjoy the fourth source of boosting efficacy beliefs; since, as Bandura's theory of self-efficacy states people's efficacy judgments are under the influence of their emotions (Sutton \& Wheatley, 2003). 


\section{Conclusion}

The present study sought to investigate the relationship between university teachers' EI and their self-efficacy beliefs. Furthermore, the association between teachers' self-efficacy and the 15 components of EI was examined. The findings of the study led to the conclusions that, first, there was a strong positive connection between EI and efficacy; second, three components of EI, i.e., Flexibility, Optimism and Interpersonal Relationship, were found to be positive predictors of university teachers' efficacy beliefs.

Officials responsible for constructing higher education are advised to provide facilities for holding some workshops, conferences and training courses for university instructors, at least for the less experienced ones, in which the concept of EI would be introduced, its importance in effective teaching and the development of teacher self-efficacy would be discussed and the strategies for its development would be proposed.

Lecturers and instructors are advised to take into consideration the emotional dimensions as influential as cognitive aspects in their development. Therefore, they are recommended to develop the abilities and skills connected with EI. To this end, taking into account the three components of Flexibility, Optimism and Interpersonal Relationship is of greater importance. University instructors are recommended to devote more office hours for their students since interpersonal relationship as this study and other studies (e.g., Moafian \& Ghanizadeh, 2009) revealed, is a strong predictor of efficacy beliefs.

It is highly recommended that Instructors practice flexibility by devoting some class time for listening to students' comments and criticisms and admit the apt ones. They can also benefit from discussing these points with their colleagues in order to improve their teaching and obviate deficiencies.

Professors are also recommended to practice more optimism toward their students. This can take place if professors trust students and give them more responsibilities such as involving them in designing course syllabus, listening to their say about how to conduct the class, etc. Students can also be given some marginal role in deciding and preparing final exam questions, correcting exam papers and also, in viva sessions, where only professors are referees, it is recommended that some room be given to students so that they can act as the jury. This feeling of optimism toward students and trust in their capabilities in addition to benefitting students in helping them develop more autonomy, confidence and responsibility, assists instructors in developing more self-efficacy.

Nevertheless, the limitations of the study should be taken into account. In this study all the participants were male. A similar study is required in which the association between the two main variables of the study is evaluated among female university instructors to see whether identical results would be obtained. Furthermore, a similar study is needed to investigate this relationship between older university instructors with more experience since the instructors in this study were proportionately younger and less experienced with average age of 27.97 and 2.64 years' experience of teaching at university.

\section{REFERENCES}

Bandura, A. (1977). "Self-efficacy: Toward a unifying theory of behavioral change", in Psychological Review, 84(2): 191-215.

Bar-On, R. (1997). The Emotional Quotient Inventory (EQ-I): Technical Manual. Toronto: MultiHealth Systems. 
Bar-On, R. (2000). "Emotional and social intelligence: Insights from the emotional quotient inventory (EQ-I)", in R. Bar-On \& J. D. Parker (eds.), The Handbook of Emotional Intelligence. San Fransisco: Jossey-Bass.

Bar-On, R., (2006). "The Bar-On model of emotional-social intelligence (ESI)", in Psicothema 18(suppl.): 13-25.

Brackett, M. A., \& Salovey, P. (2006). "Measuring emotional intelligence with the Mayer-SaloveyCaruso emotional intelligence test (MSCEIT)", in Psicothema, 18 (Suppl.): 34-41.

Caprara, G, V., Barbaranelli, C., Steca, P., \& Malone, P. S. (2006). "Teachers' self-efficacy beliefs as determinants of job satisfaction and students' academic achievement: A study at the school level", in Journal of School Psychology, 44: 473-490.

Carmeli, A. (2003). "The relationship between emotional intelligence and work attitudes, behavior and outcomes", in Journal of Managerial Psychology, 18(8): 788-813.

Cayanus, J. L. (2005). Students' Propensity to Ask Questions: Do Cognitive Flexibility, Teacher Self-Disclosure, Student Motives to Communicate, and Affective Learning Influence Question Asking in the Classroom? Unpublished doctoral dissertation, West Virginia University, Utah.

Chan, D. W. (2004). "Perceived emotional intelligence and self-efficacy among Chinese secondary school teachers in Hong Kong", in Personality and Individual Differences, 36(8): 1781-1795.

Chan, Y. M. (2006). Examining Teacher Hoped for Selves among Pre-Service, New, and Experienced Teachers. Unpublished doctoral dissertation, Texas Tech University.

Coladarci, T. (1992). "Teachers' sense of efficacy and commitment to teaching", in The Journal of Experimental Education, 60(4): 323-337.

Dehshiri, R. (2003). The Reliability and Validity of EQ-i in Iran's Context. Unpublished master's thesis, Allame Tabatabaee University, Tehran, Iran.

Evers, W. J. G., Brouwers, A., \& Tomic, W. (2002). "Burnout and self-efficacy: A study on teachers' beliefs when implementing an innovative educational system in the Netherlands", in British Journal of Educational Psychology, 27: 227-243.

Fabio, A. D., \& Palazzeschi, L. (2008). "Emotional intelligence and self-efficacy in a sample of Italian high school teachers", in Social Behavior and Personality: An international Journal, 36(3): 315-326.

Gardner, H. (1983). Frames of Mind: The Theory of Multiple Intelligences. New York: Basic Books.

Gibbs, C. (2002). Effective teaching: Exercising self-efficacy and thought control of action. Paper presented at the Annual Conference of the British Educational Research Association, University of Exeter, England.

Goleman, D. (1995). Emotional intelligence. New York: Bantam.

Jarvis, M. (2005). The psychology of effective learning and teaching. London: Nelson

Karademas, E. C., Kafetsios, K., \& Sideridis, G. D. (2007). "Optimism, self-efficacy and information processing of threat-and well-being related stimuli", in Stress and Health, 23: 285-294.

Larson-Hall, J. (2010). A guide to doing statistics in second language research using SPSS. New York and London: Routledge.

Lowman, J. (1996). "Characteristics of exemplary teachers", in New Direction for Teaching and Learning, 65: 33-40.

Luszczynska, A., Gutiérrez-Doña, B., \& Schwarzer, R. (2005). "General self-efficacy in various domains of human functioning: Evidence from five countries", in Interpersonal Journal of Personality, 64: 873-898. 
Moafian, F. \& Ghanizadeh, A. (2009). "The relationship between Iranian EFL teachers' emotional intelligence and their self-efficacy in language institutes", in System, 37(4): 708-718.

Mortiboys, A. (2005). Teaching with emotional intelligence: A Step-by-Step guide for higher and further education professionals. London: Routledge.

Pajares, F. (2001). "Toward a positive psychology of academic motivation", in The Journal of Educational Research, 95(1): 27-35.

Pajares, F. (2002). Overview of social cognitive theory and self-efficacy, available from: http:// www.emory.edu/EDUCATION/mfp/eff.html, accessed 12 November, 2010.

Penrose, A., Perry, C., \& Bell, I. (2007). "Emotional intelligence and teacher self-efficacy: The contribution of teacher status and length of experience", in Issues in Educational Research, 17(1): 107-126.

Rastegar, M., \& Memarpour, S. (2009). "The relationship between emotional intelligence and self-efficacy among Iranian EFL teachers", in System, 37(4): 700-707.

Ross, J. A. (1994). Beliefs that make a difference: The origins and impacts of teacher efficacy. Paper presented at the annual meeting of the Canadian Association for Curriculum Studies

Salovey, P., \& Mayer, J. D. (1990). "Emotional intelligence", in Imagination, Cognition and Personality, 9: 185-211.

Schunk, D. H., \& Meece, J. L. (2005). "Self-efficacy development in adolescence", in F, Pajares \& T. Urdan (eds.), Self-efficacy beliefs of adolescents. Greenwich, CT: Information age publishing.

Schutte, M. S., \& Malouff, J. M. (1999). Measuring emotional intelligence and related construct. Lewiston: Edwin Mellen Press.

Schutte, M. S., Malouff, J. M., Hall, L. E., Haggerty, D. J., Cooper, J. T., Golden, C. J., \& Dornheim, L. (1998). "Development and validation of a measure of emotional intelligence", in Personality and Individual Differences, 25: 167-177.

Shnek, Z. M., Irvine, J., Stewart, D., \& Abbey, S. (2001). "Psychological factors and depressive symptoms in ischemic heart disease", in Health Psychology, 20: 141-145.

Sutton, R. E., \& Wheatley, K. F. (2003). "Teachers' emotions and teaching: A review of the literature and directions for future research", in Educational Psychology Review, 15(4): 327-358.

Tschannen-Moran, M., \& Woolfolk Hoy, A. (2001). "Teacher efficacy: Capturing and elusive construct", in Teaching and Teacher Education, 17: 783-805.

Tseng, S. C., \& Tsai, C. C. (2010). "Taiwan college students' self-efficacy and motivation of learning in online peer assessment environments", in Internet and Higher Education, doi: 10.1016/j.iheduc. 2010.01.001.

Vickers, K. S., \& Vogeltanz, N. D. (2000). "Dispositional optimism as a predictor of depressive symptoms over time", in Personality and Individual Differences, 28: 259-272.

Williams, M., \& Burden, R. (2000). Psychology for Language Teachers: A Social constructivist approach. Cambridge: Cambridge University Press.

Wong, C. S., \& law, K. S. (2002). "The effects of leader and follower emotional intelligence on performance and attitude: An exploratory study", in The Leadership Quarterly, 13: 243-274.

Woolfolk H., A., Hoy, W. K., \& Kurz, N. M. (2007). “Teacher's academic optimism: The development and test of a new construct", in Teaching and Teacher Education, 24(4): 821-835.

Wubbels, T., \& levy, J. (1991). "A comparison of interpersonal behavior of Dutch and American teachers", in International Journal of Intercultural Relations, 15: 1-18.

Zimmerman, B. J. (2000). "Self-efficacy: An essential motive to learn", in Contemporary Educational Psychology, 25: 82-91. 